\title{
La representación
}

política en Puebla

(entrevista al doctor

Raymundo García)*

/ Political

Representation in

Puebla (Interview

with Doctor

Raymundo García)

* Recibido: 17 de junio de 2015. Aceptado: 13 de julio de 2015.

Tla-Melaua, revista de Ciencias Sociales. Facultad de Derecho y Ciencias Sociales.

Benemérita Universidad Autónoma de Puebla, México / IssN: 1870-6916 / Nueva Época,

Año 9, No 39, octubre 2015/marzo 2016, pp. 80-91. 
RESUMEN

Entrevista realizada en Ciudad Universitaria, Facultad de Derecho y Ciencias Sociales de la Benemérita Universidad Autónoma de Puebla. Martes 3 de diciembre de 2013. El interés por conocer los puntos de vista del entrevistado se dan en el desarrollo de mi proyecto de investigación sobre el sistema electoral de México, donde analizo el caso federal, y los de Tlaxcala, Puebla, Chiapas y Veracruz, además de Costa Rica y Chile. Específicamente, busqué a Raymundo García 2 para discutir el caso de Puebla. La presentación no tiene un formato específicamente de entrevista, porque fue más bien una charla, de la cual guardo la grabación de audio y notas escritas. Se usará la primera persona para la voz del doctor García, específicamente cuando habla de la publicación de su libro, su propuesta de reforma como legislador, o su adscripción partidista. Asumo las notas a pie de página. El fondo del artículo está constituido por ideas compartidas en la charla.

\section{PALABRAS CLAVE}

Sistema electoral, representación política, proporcionalidad, partidos políticos.
A B S T R A C T

Interview made in the University City, Faculty of Law and Social Sciences of the Benemérita Universidad Autónoma de Puebla (Meritorious Autonomus University of Puebla). Tuesday, 3rd December, 2013. My interest to know the points of view of the interviewee is given in the development of my own research project about the electoral system in Mexico.

I analyze the federal case, and the ones from Tlaxcala, Puebla, Chiapas and Veracruz. Additionally, I analyze the ones from Costa Rica and Chile.

I discussed with Raymundo García the specific case of Puebla. The presentation does not have a specific interview format, because it was a talk, from which I keep the audio recording and written notes. For the voice of Dr. García, I use the first person singular, specifically when he speaks about the publication of his book, his reform proposal as a legislator, or his party affiliation. The bottom of the article is constituted by shared ideas from our talk.

KEYWORDS

Electoral System, Political Representation, Proportionality, Political Parties.

\footnotetext{
* Profesor investigador en la Facultad de Derecho y Ciencias Sociales de la Benemérita Universidad Autónoma de Puebla, México. (frasaes_7@hotmail.com).
} 
1. Las bases desde la teoría para abordar lo políticoelectoral / 2. Los orígenes en el caso de Puebla / 3. Representación política

1. LAS BASES DESDE LA TEORÍA PARA ABORDAR

LO POLÍTICO-ELECTORAL

Para hablar de temas como los sistemas electorales, temas de decisión política, es necesario arribar al realismo político. Es decir, para llegar a la idea de la norma jurídica como una decisión política hay que retomar a Maquiavelo, ${ }^{1}$ Hobbes $^{2}$ y, sobre todo, a Austin ${ }^{3}$ con su teoría del soberano, y llegar hasta los pensadores como Hart ${ }^{4}$ y Kelsen. ${ }^{5}$ En dichos autores lo que se inscribe en la norma es la búsqueda de una determinada conducta humana. Toda esta es la carga filosófica que hay detrás del enfoque del realismo político norteamericano y que en México de alguna forma se instituye.

¿Qué sucede en el campo político electoral? Ahí las normas jurídicas, con mayor razón, son un acuerdo político; son una decisión política en la cual incluso se rompen teorías y doctrinas, y se impone el acuerdo entre los actores políticos. En la representación política, en un principio, se tuvo la regla de mayoría absoluta y luego mayoría relativa. En un momento dado, fue necesario, para apuntalar al sistema mexicano, un sistema mixto con dominante mayoritario. Se utilizó la figura de diputados de partido, en 1963, y, luego, el sistema mixto desde un enfoque ya más sistematizado, más pensado, que se da en 1977 a nivel federal y se aplica en las elecciones de 1978.

\footnotetext{
${ }^{1}$ Véase Maquiavelo, Nicolás, Discursos sobre la primera década de Tito Livio, Madrid, Alianza, 1987; Maquiavelo, Nicolás, El príncipe, Madrid, Tecnos, 1998.

${ }^{2}$ Véase Hobbes, Thomas, Leviatán: o la materia, forma y poder de una república eclesiástica y civil, México, FCE, 2002.

${ }^{3}$ Véase Austin, John, The province of jurisprudence determined, Cambridge, Cambridge University Press, 1995.

${ }^{4}$ Véase Hart, Herbert, Derecho y moral. Contribuciones a su análisis, Buenos Aires, Editorial Depalma, 1961; Hart, Herbert, El concepto de derecho, Buenos Aires, Abeledo Perrot, 1992.

${ }^{5}$ Véase Kelsen, Hans, Teoría general del derecho y del Estado, México, Imprenta Universitaria, 1949.
} 


\section{LOS ORÍgenes EN EL CASO DE PUEBLA}

Esos cambios realizados a nivel federal en Puebla se vienen a desarrollar y aplicar hasta la década de los ochenta. Puebla tiene históricamente un régimen autoritario que no se creó con el PRI, sino que es consecuencia de su sistema político, formado desde que se constituyó como estado federado. En su origen, fue una entidad federativa donde el poder legislativo era muy fuerte; pero en 1861 se construyó un modelo centralizado del poder en manos del ejecutivo.

Este es un elemento que está presente en Puebla, y posiblemente en otros estados también. El gobernador, como gran legislador, hace la ley electoral de acuerdo con sus intereses. No interesa la voluntad general, ni el beneficio de un partido político. Muchas veces pensamos "pues es para el interés del PRI”. ¡No! Lo que se quiere es construir una norma jurídica que lo apoye, que le dé fuerza al gobernador, aunque la ley sea aberrante. Citemos un ejemplo: en el siglo XIX se decía que el poder ejecutivo lo integraban el gobernador, los secretarios de despacho, los jefes políticos, los ayuntamientos: es una aberración.

El poder ejecutivo lo debe integrar una sola persona. Sin embargo, lo que estaba así creándose es un ejecutivo colectivo, donde a la cabeza está el gobernador y todas las demás autoridades que se mencionan, las cuales llegan hasta el pueblo más alejado de la capital, y dependen directamente del gobernador. ${ }^{6}$ El autoritarismo se establece, en el caso de Puebla, desde la constitución. Inclusive demuestra que el poder ejecutivo en Puebla es superior al legislativo.

Después vienen reformas. Pero en el caso de Puebla hay un fenómeno muy interesante. Cuando se habla de la división de poderes, se habla de departamentos: el departamento del ejecutivo, del legislativo, del judicial. Sin embargo, hay una disposición especial que dice que el legislativo representa la soberanía del Estado y puede cambiar leyes, siempre y cuando no atenten contra el interés general y que el ejecutivo esté de acuerdo. Es algo verdaderamente de no creerse: es en la Constitución de Puebla donde queda plasmado

\footnotetext{
${ }^{6}$ En la Constitución Política del Estado de Puebla 1861, del 20 de septiembre, en el título segundo "De la forma de gobierno", pueden leerse los dos artículos siguientes:

" $5^{\circ}$. El Estado de Puebla adopta para su régimen interior el gobierno republicano representativo, popular federal.

$6^{\circ}$. El ejercicio del supremo poder del Estado se divide en legislativo, ejecutivo y judicial. El primero reside en el Congreso. El segundo en el gobernador y sus secretarios, los jefes políticos y ayuntamientos y el tercero en los ministros de los tribunales superiores, jueces de primera instancia, alcaldes y jueces de paz, no pudiéndose reunir dos o más poderes en una persona o corporación ni depositarse el legislativo en un individuo." (Puede consultarse en el apéndice de: Coutiño, Fabiola, Las legislaciones electorales del siglo XIX en Puebla, México, Limusa, 2012).
} 
que el poder Legislativo está subordinado al Ejecutivo. ${ }^{7}$ Con estos datos, se observa que la legislación (luego veremos que también la correspondiente a lo electoral) se convierte en la principal arma de control del poder y se va a utilizar combinada con la soberanía del estado.

No importa que a nivel federal haya cambios; si a nivel estatal no conviene al gobernador, no se hacen los correspondientes en la legislación local. Si no se hubiera presionado desde la sociedad para que el cambio se generara, no hubiera sucedido que en 1963 se crearan los diputados de partido a nivel federal. Aquí en Puebla se crearon hasta 1977, o sea, quince años después. Otro aspecto relacionado con la representación política, y que sirve como un ejemplo adicional, es el voto de las mujeres. Se reconoció en Puebla en 1936; pero la cuota de género se introdujo en 1996, y en materia electoral hasta el año 2000, para que se aplicara hasta el 2001.

\section{REPRESENTACIÓN POLÍTICA}

\subsection{Los porcentajes}

La representación política, que es el tema central, es un modelo mixto con dominante mayoritario, y se viene manejando con criterios administrados. Por ejemplo, a nivel federal se establece una relación de $60 \%$ a $40 \%$. A nivel de las entidades federativas esa relación tiene variantes; en Puebla, esa relación tampoco existe. Otro caso, como lo dejé anotado en el libro que escribí sobre legalidad y conflictos en Puebla, ${ }^{8}$ es que al referirse al número de diputados de representación proporcional la ley dice "hasta". Esto representa un ejemplo de la interpretación constitucional de lo que mejor convenga: si se dijera, por ejemplo, hasta nueve diputados, entonces a la hora de aplicar la ley, pueden ser tres, cuatro, cinco; porque hasta significa un máximo de nueve diputados. No es lo mismo que diga que se integrará con nueve diputados

\footnotetext{
${ }^{7}$ En la Constitución Política del Estado Libre y Soberano de Puebla de 1861, reformada en 1894, pueden leerse los artículos:

"Art. 21. El Estado adopta para su régimen interior la forma de gobierno republicano, representativo, popular.

Art. 22. El poder público del Estado se considera dividido, para el ejercicio de sus funciones, en tres departamentos: Legislativo, Ejecutivo y Judicial. Cada uno de estos departamentos se organizará en la forma que más adelante se establece, y nunca podrá confiarse el ejercicio simultáneo de las facultades de dos o más de ellos a una sola persona o corporación."

Luego se abre una posibilidad con las "disposiciones especiales":

"Art. 24: Por regla general, y salvo disposiciones especiales de esta constitución, corresponde: Al departamento legislativo dictar las leyes; al departamento ejecutivo vigilar la observancia de ellas y aplicarlas, dando reglamentos, acuerdos, órdenes y circulares relativas a puntos de interés o de aplicación general."

La fracción vigésima del artículo 39 referido a las facultades del congreso dice: "Conceder al gobernador facultades extraordinarias en las diversas ramas de la administración, cuando así lo exijan las circunstancias y lo acuerden los dos tercios de los diputados presentes."

${ }^{8}$ García García, Raymundo, Puebla: elecciones, legalidady conflictos municipales 1977-1995, Puebla, BUAP, 1998.
} 
de representación proporcional; entonces sería claro. Pero la redacción está diseñada para satisfacer intereses particulares. Hay un momento en el cual hay todo un conflicto poselectoral, porque no se cumple la distribución de los nueve diputados. Sucede lo mismo en el caso de las regidurías.

¿Qué sucede al transcurrir el tiempo en el ámbito federal? El sistema de representación política con dominante mayoritario va progresando. Se inicia con minorías en $25 \%$ frente a 75 , después sube a $30 \%$ frente a $70 \%$, se reajusta con 33 frente a $67 \%$. Finalmente sube a 40 con 60\%. Es decir, a nivel federal se va dando toda una transformación de la representación política. Pero ese movimiento, que llega a su total expresión en 1996 en Puebla, tiene una característica: va atrasada en el asunto de las reformas electorales.

A pesar de que haya un mandato constitucional que obliga a incorporar el sistema mixto de representación proporcional a las entidades federativas, no les dice qué porcentajes manejar. ${ }^{9}$ Mientras en la Constitución Política de los Estados Unidos Mexicanos no quede establecido un porcentaje, cada estado, y este es un punto central, puede poner el porcentaje que quiera. Entonces, ¿qué tenemos? Treinta y dos sistemas de representación política con elementos diferentes. Ni siquiera se explica por qué en algunos son unos porcentajes y en otro caso son otros.

\subsection{El multipartidismo}

En Puebla, para aparentar un avance en materia de representación política, Manuel Bartlett hizo una primera reforma en 1995. Parece de gran apertura democrática hacia los partidos, pero se convierte en una trampa para los partidos grandes que no gobiernan, y que están como segunda y tercera fuerza: PAN y PRD. El gobernador y su partido están preocupados por encontrar una forma para que las oposiciones no puedan avanzar, no puedan fortalecerse con el sistema de diputados de representación proporcional.

Desde luego, esta es una lectura, posiblemente puede haber otra que argumente que las oposiciones no son competitivas. Por lo tanto, aunque la ley es buena, no ganan la posibilidad de tener mayor representación, pero conviene revisar el papel de la ley. El sistema de representación que creó Bartlett, a diferencia del federal, se mueve en tres niveles: tiene una cuota de porcentaje mínimo, primero de $1.5 \%$ y ahora es de $2 \%$; un reparto por

\footnotetext{
${ }^{9}$ En el artículo 116, párrafo segundo, incluso con la reforma del 10 de febrero de 2014, puede observarse que no se especifican los porcentajes:

II. Las legislaturas de los Estados se integrarán con diputados electos, según los principios de mayoría relativa y de representación proporcional, en los términos que señalen sus leyes. Constitución Política de los Estados Unidos Mexicanos. [Consulta: 23 de febrero, 2015]. Disponible en: http://www.upq.mx/ uploads/documentos/normatividad/constitucionmexico.pdf
} 
cociente electoral; y, si quedaran diputados por repartir de representación proporcional, tendrá una asignación por resto mayor.

Entonces, con una cuota mínima de $\%$, se va a golpear a las fuerzas políticas de oposición a través de la creación de muchos partidos políticos. Es decir, dentro de un sistema de multipartidismo, o en términos de Sartori de pluralismo alto no limitado, son más de cinco partidos. Entonces, entre mayor sea el número de contendientes, menor será la representación que tengan los partidos más grandes. Ese es el juego. ¿Por qué? Porque todos los que tengan $2 \%$ ingresan a obtener un diputado.

Si se toman en cuenta las reformas, incluso se llega a seis diputados de representación proporcional. Si hay siete partidos políticos, en automático se le quitan a trece, y quedan seis. Entonces, realmente el sistema se reduce a seis de representación proporcional, cuando era de nueve. De nueve subió a trece, pero con las reformas regresó prácticamente a seis. Alguien puede argumentar que es más equitativo, y puede que así sea, pero se rompe el sentido del planteamiento teórico.

¿Cuál es el sentido de la representación proporcional? Disminuir los desequilibrios que genera el sistema de mayoría. Pero si se generan disposiciones jurídicas que tengan lagunas, esto va encaminado precisamente a que los partidos que sean la segunda y tercera fuerza electoral se vean menos representados, y que el partido predominante o el mayoritario se vean sobrerrepresentados. Entonces, la característica del sistema poblano es que hay una pugna o un trabajo jurídico para mantener la sobrerrepresentación del partido más grande.

\subsection{Vuelta a los porcentajes}

Si este modelo de sobrerrepresentación del partido más grande se mantiene a través de la multipartidización, entonces, desde su poder, el gobernador y su partido darán aliento a la creación de otros de orden estatal. Esta forma llega a institucionalizarse ¿Cómo lo hacen? Pues en la norma se dice que a los partidos que obtengan el porcentaje mínimo se les asignará un diputado, pero el valor de ese diputado altera la idea del cociente electoral ¿Por qué? Este es el punto central.

No es lo mismo dividir la votación efectiva entre un número de diputados de representación proporcional para generar un cociente electoral y en función de eso hacer la asignación (como estaba originalmente en Puebla) que, por otro lado, en un discurso de democratización, generar una asignación por porcentaje mínimo. El porcentaje mínimo se convierte en un instrumento de represión en contra de los partidos de oposición grandes y en un aliciente para los pequeños, los cuales, por el hecho de tener $2 \%$ de votos, van a obtener un diputado. El problema es que se les da a todos, a los grandes y a los chicos; ello genera una gran inequidad. 
Entonces, en la reforma del 2000 se subió a quince el número de diputados de representación proporcional. Si consideramos, por ejemplo, que hubiera siete partidos concursando y que todos alcanzan $2 \%$, entonces a quince se le quitarían siete y quedarían ocho diputados de representación proporcional. Esos ocho se llevan a sacarles cociente electoral y en función de eso se efectuaría el reparto. ¿Qué sucede? Que el partido más grande se sobrerrepresenta, porque además si gana y gana todas se va a sobrerrepresentar de todos modos, a pesar de que ganando todas ya no puede tener más de veintiséis diputados por ambos principios. Ahí estamos en otro problema.

\subsection{El tamaño de la cámara}

Ese nuevo problema es que si la cámara de diputados tiene 41 diputados, y si veintiséis es el máximo que puede obtener un partido, quince son de representación proporcional, teóricamente reservados a la oposición. Entonces, se está generando un modelo matemático diferente al que se tiene a nivel nacional ¿En qué? Se está generando una relación de 63 y 37\% para los dos principios, mayoría relativa y representación proporcional.

Este es un problema que prácticamente no se cuestiona, cuando a nivel nacional la relación es de 60 a 40\%. Esto significa que, con la normatividad, el partido mayoritario le quita un diputado a las minorías. Una relación de 60 a 40 significaría que ningún partido pudiera tener más de veinticinco diputados: no puede tener veintiséis. ${ }^{10}$ Entonces, aquí se demuestra lo que históricamente ha sucedido en el estado de Puebla: la ley viene rezagada y se utiliza en beneficio del grupo que está en el gobierno.

\subsection{La primera asignación}

Otro subtema relevante de la reforma del 2000 es que se creó el porcentaje mínimo, ligado con la primera asignación, a la cual se le denomina coloquialmente "diputado gran perdedor" o "mejor perdedor". Esto tiene diversas interpretaciones. Una cuestión es por qué toma en cuenta el porcentaje de

\footnotetext{
${ }^{10}$ Los porcentajes precisos con veintiséis diputados de mayoría relativa y quince de representación proporcional son 63.41 y $36.59 \%$, respectivamente, cuando a nivel federal la proporción es de 60 a 40\%. Es cierto que para respetar esos porcentajes ningún partido podría tener más de veinticinco diputados, y no veintiséis, como señala la norma electoral. No obstante, aún veinticinco diputados significan $60.97 \%$ de un total de 41. Por lo tanto, aún tendría que considerarse bajar a veinticuatro diputados, como máximo. Ninguna de estas opciones parece viable, porque tendrían que desconocérsele triunfos de mayoría relativa en distritos uninominales a un partido que obtuviera veintiséis diputados por este principio. Por lo tanto, parece más viable aumentar el número de diputados de representación proporcional a diecisiete. De esa manera, los porcentajes quedan como 60.47 y $39.53 \%$ con un total de 43 diputados. $\mathrm{Si}$, en un intento por igualar los porcentajes con el nivel federal, se elevara el número de diputados de representación proporcional a dieciocho, para un total de 44 diputados, los porcentajes quedarían 59.09 y 40.91, respectivamente. Por lo tanto, la desviación se hace mayor, ya que con diecisiete diputados es de 0.47 , y con dieciocho sería de 0.91 .
} 
votación y no el número de votos. El sistema está hecho para que los diputados "grandes perdedores" salgan de los distritos urbanos, y sólo excepcionalmente van a salir de los distritos semiurbanos. Esto es porque la competencia tripartidista se da en medios no urbanos, y ahí en donde ésta sucede se tensan los porcentajes y no permite que la segunda fuerza tenga alto porcentaje. Para dejarlo más claro: si partimos del supuesto de que la representación política, como dice la constitución, está montada en representar a la población, ${ }^{11}$ no tiene que ser porcentaje, sino votos. Entonces, la mejor representación de las minorías sería tomar al candidato de minoría con más votos, no con más porcentaje.

Como legislador, quise proponer que fuera número de votos y me dijeron que no. El Partido Acción Nacional dijo que no porque es más fácil, más controlable, el porcentaje que el número de votos. Aquí hay un discurso contradictorio del PAN: por un lado, alienta desde sus viejas propuestas que hay que generar una representación por la competitividad electoral, y no por el asunto de la constancia del asentamiento que generan las elecciones; por otro, prefiere lo controlable.

\section{6 El cociente electoral}

Para cerrar, hubo una reforma en el año 2007 de carácter electoral. En materia de representación proporcional, la propuesta fue mía. Al asignar diputados "gran perdedor", que supone cumplir con $2 \%$, no se disminuía el valor del número de votos de ese $2 \%$ para calcular el cociente electoral. Este fenómeno le pegaba a los partidos que ocupaban el lugar de segunda y tercera fuerza electoral. Entonces, lo que se hace en esta reforma es introducir la disposición de que se reste el valor de $2 \%$ de la votación.

Para el procedimiento se debe obtener de $2 \%$ de la votación. Ese porcentaje es la cantidad de votos que garantiza a las minorías acceder al poder legislativo, ese mismo número se le resta a los partidos políticos, lo cual constituye la votación total y ahora sí se saca el cociente. Esto permitió, por ejemplo, que el partido en segundo lugar pudiera alcanzar un diputado más, que es el que se le robaba en la forma de redacción anterior.

Es muy importante ver la redacción. No es que haya un modelo matemático que funcione para el caso de Puebla y debamos encontrarlo, sino que son visiones particulares del legislador, quien utiliza la ley para aterrizar en la

\footnotetext{
${ }^{11}$ Efectivamente, lo que se toma en cuenta es la representación de la población. El artículo correspondiente en la Constitución Política de los Estados Unidos Mexicanos dice: "Artículo 53. La demarcación territorial de los 300 distritos electorales uninominales será la que resulte de dividir la población total del país entre los distritos señalados. La distribución de los distritos electorales uninominales entre las entidades federativas se hará teniendo en cuenta el último censo general de población, sin que en ningún caso la representación de un estado pueda ser menor de dos diputados de mayoría”.
} 
realidad intereses muy particulares. Aunque se actualice automáticamente y se le dé una explicación matemática a una situación electoral y de reparto proporcional, que sí la tiene y es necesario analizar, se vuelve a que las estructuras constitucionales están hechas para garantizar un partido mayoritario fuerte.

Efectivamente, es interesante verificar si cambiaría la distribución de diputaciones descontando 2\% y sin hacerlo. Los resultados para la elección 2010 se presentan en el cuadro 1; los resultados, sin hacer el descuento de los votos correspondientes a $2 \%$, en el cuadro 2 : 
No hay diferencias, se trata de una elección con pocas fuerzas electorales en competencia. Para verificar qué pasaría en un sistema multipartidista se presenta, en los cuadros 3 y 4 , la simulación de la legislación poblana, con y sin descuento de $2 \%$, pero tomando los resultados electorales del mismo año 2010, en Tlaxcala:

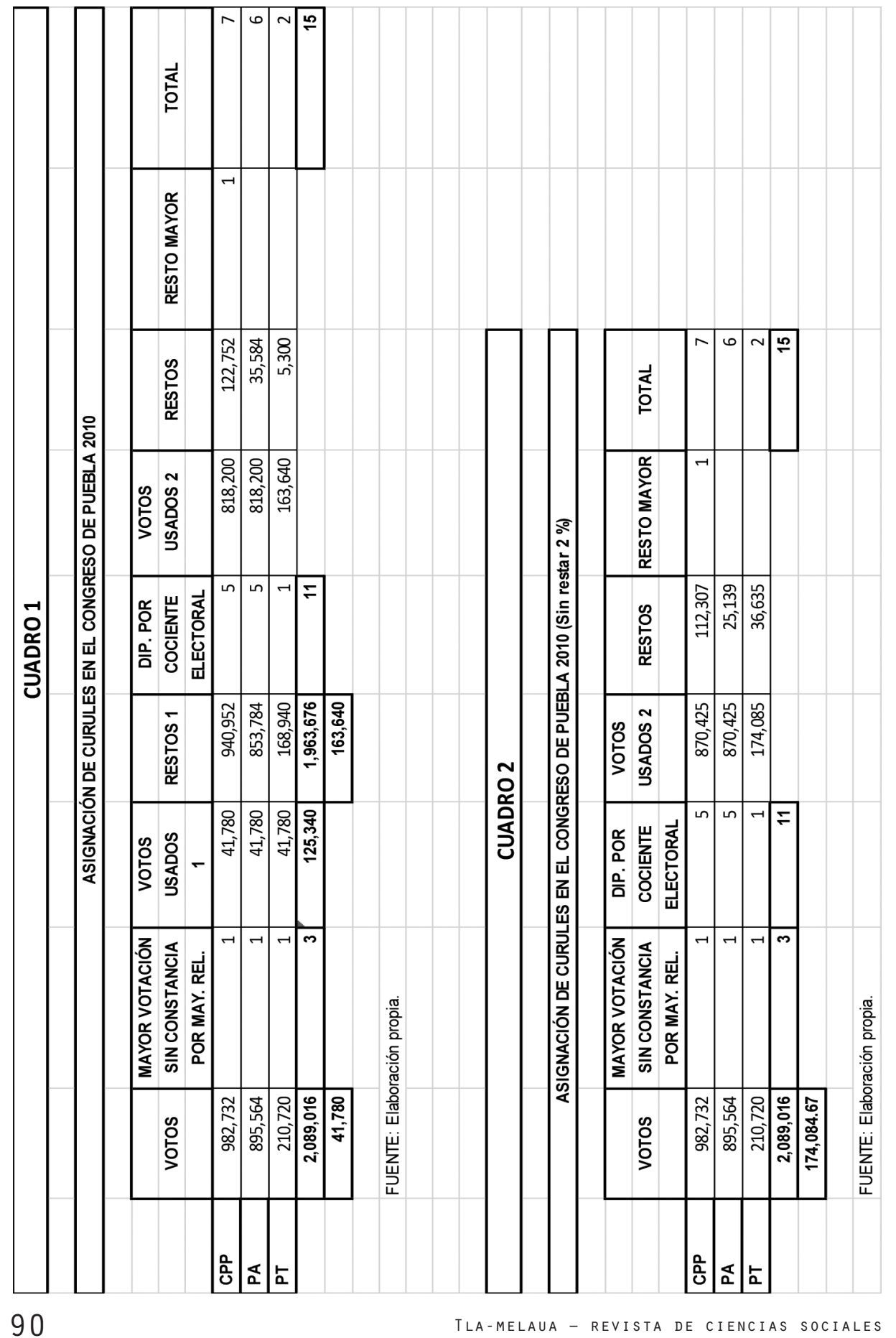


Puede verse que en contextos multipartidistas sí hay diferencia. El índice de proporcionalidad aumenta cuando se descuenta $2 \%$ de votos, pero la primera fuerza gana un diputado y los minoritarios la pierden (en este caso el PCDT). No obstante, la primera fuerza sigue subrrepresentada.

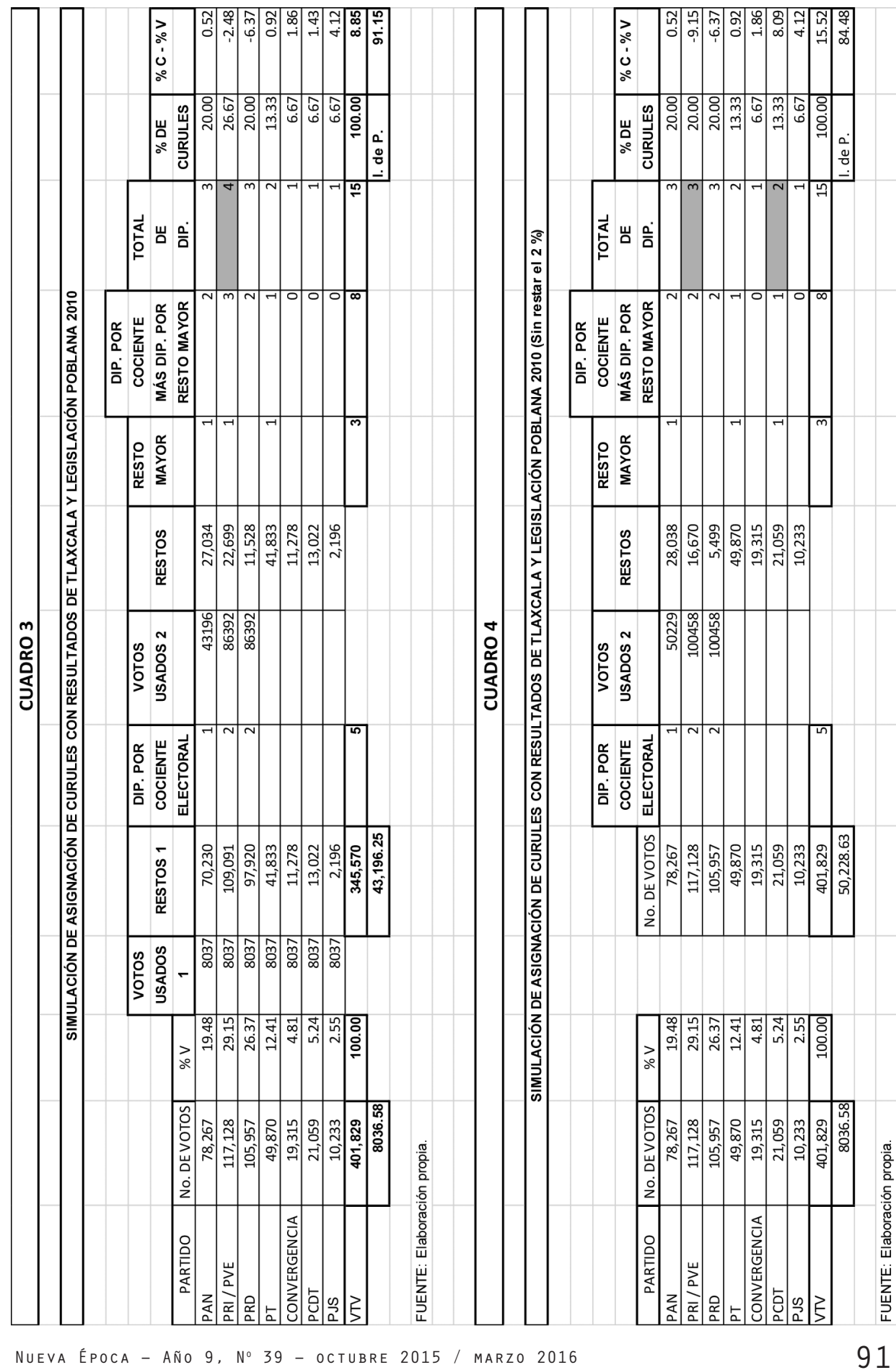

